\title{
Does the cover letter really matter?
}

\author{
Khaled Moustafa*
}

\begin{abstract}
Many journals require a covering letter alongside the submission process. Some of them, particularly elitist journals, pay a particular attention to the cover letter to such extent an editor may decide not to send a paper out for external peer-review because of a 'bad' or absence of covering letter. As stated in the instructions of many journals, the goal of covering letter is to emphasize the novelty and to communicate the potential implications of the reported findings. Authors are also invited to tell the handling editor how the topic is related to the journal's scope and to demonstrate how the results fit in broader context of the literature.
\end{abstract}

Keywords: cover letter, manuscript submission

A closer examination of these requirements indicates that the cover letter should present a 'summary' of the work and to highlight the main points and major implications of the submitted manuscript. In other words, in the cover letter authors should convey the fundamental elements of the research being reported to the attention of the evaluating editor and reviewers. If, however, we look closely at the objective of the articles' abstracts, we realize that the content of the cover letter is, should be, covered in the abstract. The instructions or recommendations for writing 'good' abstracts stipulate that authors should stress the importance/novelty/implications of the work to draw the attention of, not only the evaluators, but also the attention of a broader panel of readers.

The advocates of the cover letter say that the cover letter is the place to 'convince' the handling editor to send the manuscript out for external peer-review! As such, authors should ask the following question: if a strong and cogent statement of the abstract and the manuscript itself are not able to 'convince' an editor, how truncated, 'ornamental', often 'artificial' cover letter could convince objectively? If an editor, particularly in the elitist journals which pay great attention to the cover letter, is not able to draw the importance of a manuscript in his hands, why and how an editorial position of that importance is filled in the so-called 'highly-ranked journals'.

The abstract is the most important and perennial section of a manuscript that authors should load with the most convincing argumentations because it is intended to be indexed and read by many more people than a cover letter, which is destined to be read by a few 
people at the editorial level only. One can thus legitimately wonder what kind of convincing arguments would remain to be included specifically in a cover letter to 'convince' the editor of whatever importance? If the goals of the cover letters are already covered elsewhere in the manuscript, particularly in the abstract and concluding paragraphs, and unless some editors do not read the submitted manuscripts before making decision, why journals ask authors to provide a cover letter?

I couldn't find the exact origin of the cover letter; why and how it was introduced into the scientific field. Maybe its origin finds roots in the aristocracy, business and banking sector, but whatever its origin and circumstances of its introduction into science, the cover letter is merely decorative, artificial, misleading and hyperbolizing in many cases. For authors and applicants, it is also time consuming, daunting, tedious and repetitive. A lucrative industry has been built around the supposed 'power' and 'virtues' of the cover letter. Specialized workshops, books, guidelines, tools, etc., are continually dedicated to designate the 'winner' or winning cover letter and to artificialize its content in the jungle of the job marketing. Such tools add a further superficial dimension to the cover letter as they offer an easily imitative way for authors to cover their applications or submissions with similar, overlapped and typical letters.

If a "highly ranked journal" receives for example 10,000 articles/year (some journals receive more according to their websites), and editors spend about 1 minute on reading a cover letter, the time spent (wasted!) on reading cover letters alone would be one ten thousands minutes ( 166,6 hour) per year. Without cover letters, editors would save $\sim 21$ work day of 8 hours/day per year (166/8=21,75 day)! If they spend 30 or 15 seconds only per cover letter, the wasted times would be more than 10 and 5 days per year, respectively. If editors have extra time to spend, lose, in reading covers letters in addition to manuscripts, this is another question.

The same applies on the pre-submission inquiries that many journals require before full submission of manuscripts. If editors spend some time to read the pre-submissions inquiries, then submissions later, this means that a significant time is 'lost' twice (for reading presubmission and submission). In case of non-consideration of the pre-submissions, the time spent on reading them still a waste time, too.

The proponents of cover letters may argue that the role of a cover letter is also to state that the submitted manuscript is not under consideration by another journal, or to exclude or to include potential referees. The submission managing tools, however, already offer options to provide such information, invalidating the argument above.

Some say that the role of the cover letter is to make a "good first impression", but this impression could be misleading or biased since the cover letter might appear sounding, welltailored (e.g. based on special templates), but the paper's content might not follow. The 
opposite scenario is also possible. A 'good' manuscript could be accompanied with a minimal or 'bad' cover letter, making the importance paid to the cover letter inadequate.

If the goal of cover letter is to inform the editor how the submitted material would interest the readership, this would pose the question of how an editor or an author would know about the interests of readers in advance. No one editor does survey the interests of all readers to claim that this or that article would interest them. Moreover, readers' interests vary in function of many factors such as the topic being discussed, the field, the importance, the age of readers, the interdisciplinary connections, and the interest of each reader individually, etc. In other words, readers' interests are as different as people themselves and nobody can guess about them in advance. One topic may interest a given reader but not another and vice versa.

Overall, the cover letter is not the main text destined to be evaluated or published. The content of the cover letter is already overlapped and redundant with the article abstract. Cover letters look like the 'misleading' commercial ads; as good or as bad as they might be, they do not change anything to the inherent value of the advertised product. The significance of a manuscript should be manifest in the 200-300 words of its abstract and along the manuscript as a whole. The aim of cover letter to impress editors, recruiters or hiring managers, would give only a false and ephemeral impression because the veritable, lasting, impression is that ulterior impression related to the innate value of the candidate (or the manuscript), not from a cover letter ending in the trash after all.

\footnotetext{
*Email : khaled.moustafa@gmail.com
} 